Таким образом, будущий педагог должен быть не просто финансового грамотным, но и являться личностью, умеющей применять свои способности для достижения цели, подавая объективный пример того, как гибкие навыки могут быть полезны ученикам. Для подготовки педагога, соответственно, преобладают творческая и научная направленности процесса обучения [1; 8]. В исследовании А.Э. Исламова речь идет о похожей образовательной парадигме, обобщенно названной «проективнокультурной». Поскольку методики в такой модели оперируют социокультурной и информативно-пространственной средой, в которой реализуются формируемые навыки, включая и навыки экономической компетентности [2]. Цель данной образовательной парадигмы при подготовке учителей технологии - формирование «проектирующей личности», человека, обладающего развитым проектным мышлением, уровень развития которого отображает компетентность педагога. Она проявляется как системный набор универсальных способностей учителя, совмещающих умение решать профессионально-педагогические проблемы в нестандартных ситуациях.

На основании вышесказанного, формирование экономической компетентности при подготовке будущих учителей технологии базируется на таких основных компонентах как мотивационный, когнитивный и деятельностный, которые отвечают за синтез профессиональных и личностных качеств педагога.

1. Исламов А. Э. Особенности подготовки учителя технологии в современных условиях / А. Э. Исламов // Казанский педагогический журнал. - 2017.- № 2. - С. 61-64.

2. Исламов А. Э., Адигамова Э.Б. Творческая самореализация будущего педагога в процессе проектной деятельности / А. Э. Исламов, Адигамова Э.Б. // Казанский педагогический журнал. 2018. - № 3. - С. 32-37.

3. Муллер О.Ю. Модель методической компетентности преподавателей вуза в условиях инклюзивного образования // Вестник Чувашского государственного педагогического университета им. И.Я. Яковлева. - 2019. - № 2 (102). - С. 146-152.

4. Муллер О.Ю. Реализация модели технологического профиля обучения через сетевое взаимодействие учреждений общего и профессионального образования // Известия Самарского научного центра Российской академии наук. Социальные, гуманитарные, медико-биологические науки. - 2020. - Т. 22, № 75. - С. 64-68.

5. Муллер О.Ю. Современная модель методической готовности педагогов к работе в условиях инклюзивного образования // Ценности и смыслы. - 2017. - № . 2- С. 149-158.

6. Рассказов Ф.Д., Муллер О.Ю. Научно-образовательная кластерная модель как единая система непрерывного инклюзивного пространства // Современные проблемы науки и образования. - 2016. - № 5. - https://www.science-education.ru/ru/article/view?id=25385.

7. Хлопотова Е.В. Формирование экономической компетентности будущего учителя технологии и предпринимательства : дис. ... канд. пед. наук : 13.00.08. - Челябинск, 2005. - 183 с.

8. Kosenok, S.M. The implementation of the Idea of free pedagogy in the Modern Education / S.M. Kosenok, F.D. Rasskazov, O.Yu. Muller // Modern Journal of Language Teaching Methods. - 2017. - T. 7. № 7. - C. 87-98.

9. Rasskazov F.D., Muller O.Yu. Characteristics of the model of methodological training of a teacher for working in the conditions of an inclusive educational environment // Universal Journal of Educational Research. - 2017. - № 5 (4). - C. 551-556.

\title{
Норин Н.Е., Глушков П.Ю. \\ Методы и способы развития силовых качеств у военнослужащих войск национальной гвардии Российской Федерации
}

Новосибирский военный институт имени генерала армии И.К. Яковлева войск нацииональной гвардии Российской Федеращчи (Россия, Новосибирск)

doi: $10.18411 / \mathrm{j}-03-2021-190$

idsp: ljournal-03-2021-190

\section{Аннотация}

В статье рассматриваются методы развития сильных качеств у военнослужащих войск национальной гвардии Российской Федерации. Дано краткое описание основных 
методов развития силовых способностей и причин влияющих на их развитие. Интенсивная интервальная тренировка рассматривается как актуальный метод развития физических качеств. Статья может быть полезна преподавателям физической подготовки и спорта, командирам подразделений в организации и проведении учебнотренировочных занятий.

Ключевые слова: силовые качества, мышечные волокна, сила, учебнотренировочные занятия, профессиональная деятельность, методы развития, служебнобоевая деятельность.

\section{Abstract}

The article deals with the methods of developing strong qualities in military personnel of the National Guard of the Russian Federation. A brief description of the main methods of developing power abilities and the reasons influencing their development is given. Intensive interval training is considered as an actual method of developing physical qualities. The article can be useful for teachers of physical training and sports, unit commanders in the organization and conduct of training sessions.

Key words: strength qualities, muscle fibers, strength, training sessions, professional activity, development methods, service and combat activities.I

В Наставлении по физической подготовке в войсках национальной гвардии, далее (НФП-18), методы и способы развития основных физических качеств получили своё дальнейшее развитие. Эти изменения связаны с расширением военно-прикладной направленности физической подготовки и отражают современные требования предъявляемые к военнослужащим в их повседневной служебно-боевой деятельности. Прежде всего, это относится к действиям в условиях выполнения сложных задач, которые возникают в процессе подготовки военнослужащих, сопряжённый с высоким напряжением физических и психологических качеств. В нашей статье мы постараемся более подробно остановиться на развитии силовых качеств, т.к знания в этом направлении будут способствовать стремлению к более качественному выполнению задач служебно-боевой деятельности, физическому совершенствованию, уверенности в собственных силах в сложной профессиональной деятельности.

В последнее время в специальной отечественной и зарубежной печати, посвященной методике развития физических качеств, значительное место уделяется изменениям, происходящим в мышцах человека, которые непосредственно влияют на человека, которые непосредственно влияют на физическую подготовленность. Рассматриваются новые методики развития силовых способностей человека.

Расширился круг научных изысканий в области физиологии, биомеханики и психических процессов, возникающих в организме под воздействием физических нагрузок. Первичные знания по методике развития силовых качеств у военнослужащих становятся более актуальными в ходе организации и проведения учебнотренировочных занятий и спортивного совершенствования.

Говоря о влиянии физических упражнений на организм человека, необходимо иметь представление о процессах, протекающих в мышечной ткани, строении мышц и других показателей, влияющих на развитие качества силы. Доказано, что работа эндокринной системы человека напрямую влияет на физическое состояние организма. В значительной степени рост мышечной ткани зависит от количества гормона тестостерона в нашем организме. Большой прогресс в развитии мышечной ткани будут иметь те военнослужащие, которые имеют большой уровень тестостерона, т.е . собственная эндокринная система определяет способности к росту мышечной ткани. Уровень тестостерона зависит от возраста, образа жизни, состояния здоровья и психического состояния. Однако искусственное употребление анаболиков может привести к обратному результату, вместо роста, мышечная ткань может даже 
уменьшиться. Это происходит потому, что помимо употребления стимуляторов необходима регулярная и правильная физическая тренировка, своевременно обогащающая и питающая мышечную ткань.

Кроме этого надо знать, что мышцы имеют разную длину и толщину, количество их тоже может быть разным. Важным является и тот факт, что мышцы состоят из быстрых и медленных волокон, и это соотношение тоже разное у всех людей. Все эти причины и различия в строении мышечной ткани будут, безусловно, влиять на развитие силовых способностей, но главным фактором в развитии силы всегда будет являться правильная организация тренировочного процесса. С учётом вышесказанного можно сделать следующий вывод, без регулярных тренировок мышцы будут находиться в «спячке», что скажется на их развитии не в лучшую сторону. Нужен постоянный тренировочный процесс для «прокачки» мышечной системы, развития тех или иных мышечных групп.

Для более полного представления о тренировочном процессе в развитии силовых возможностей также значение имеет окислительный процесс, непосредственно протекающий в мышечной ткани. Окислительный потенциал делит мышечные волокна на три типа: окислительные (ОМВ), промежуточные (ПМВ), гликолитические (ГМВ). Окислительные мышечные волокна содержат большое количество митохондрий, структурных единиц, из которых состоит мышечная ткань, они способны реагировать на физическую нагрузку, последующим ростом мышечного волокна. Промежуточные мышечные волокна содержат меньше митохондрий, во время мышечной работы, они утомляются быстрее и более подвержены нагрузкам.

Гликолитические мышечные волокна имеют незначительное количество митохондрий, во время физической нагрузки, они быстро накапливают «молочную кислоту» и возникает чувство «забитости» мышц. Каждый тип мышечных волокон наиболее восприимчив к тому или иному режиму тренировки, т.е. рост мышц напрямую зависит от окислительного потенциала. Это необходимо учитывать при организации учебно-тренировочного процесса. Подбор упражнений, количественные показатели, режим повторений напрямую влияют на развитие тех или иных мышечных волокон. Т.е. правильная дозировка физических нагрузок будет способствовать качественному развитию силовых способностей военнослужащих.

В Сборнике упражнений и нормативов по физической подготовке в войсках национальной гвардии Российской Федерации, новые силовые упражнения подобраны с учётом особенностей профессиональной деятельности военнослужащих. Упражнения с собственным весом, с тяжестями развивающие силовые способности применялись и ранее, но в основном они носили развивающий, общеукрепляющий характер, повышали способности проявлять силу в повседневной деятельности. Современные требования, которые получили дальнейшее развитие в НФП-18, улучшают силовые качества и навыки, необходимые не только в повседневной деятельности, но и имеют явно выраженную военно-прикладную направленность по предназначению. Мы знаем, что под понятием «сила» понимается способность человека. За счёт мышечного сокращения преодолевать воздействие внешних сил.

Различают абсолютную и относительную силу. Абсолютная сила определяется максимальными показателями мышечных напряжений без учета массы тела. Относительная сила определяется отношением силы к собственной массе тела. Физические упражнения, добавленные в НФП-18, на перекладине, с патронным ящиком в полной экипировке, характеризуют абсолютную силу, способности военнослужащих действовать в сложных условиях служебно-боевой деятельности. Соответственно, этим упражнениям изменилась и методика проведения силовых тренировок в ходе учебно-тренировочных занятий. Руководителю занятия необходимо больше внимания уделять на упражнения для укрепления суставов, связок, развитию становой силы военнослужащих. 
Практические занятия показывают, что, к сожалению, связочный аппарат, особенно нижних конечностей и спины, требует квалифицированного подхода к подбору упражнений для его развития и укрепления. На упражнения для развития силы мышц спины, ног необходимо уделять больше внимания при организации комплексных тренировок в конце занятия.

В связи с этим, возникают изменения и в методике проведения комплексной силовой тренировки. Вместе с тем, основные методы тренировки силовых способностей не изменились. К ним относятся: метод повторных усилий, максимальных усилий, до отказа, изометрических напряжений, переменных сопротивлений.

Повсеместное широкое применение этих методов показывает, что они прочно вошли в нашу практическую деятельность. Считаем, что в рамках нашей статьи нет необходимости подробно останавливаться на методике и способах их применения. Однако. Метод повторных усилий, на наш взгляд, приобрёл специфическую направленность, за счёт повышения интенсивности тренировочного процесса. Для того чтобы справиться с повышенной нагрузкой, выполняя упражнения в полной экипировке, когда вес военнослужащего возрастает на 20-30 кг, необходимо иметь подготовленную сердечно-сосудистую систему. Этого можно достичь при помощи интервальных тренировок. Выполнение упражнений должно чередоваться с небольшими фазами отдыха, т.к. физическая работа должна проходить на фоне неполного восстановления. Это лучший метод в подготовке силовой выносливости и развитии сердечно-сосудистой системы организма. При выполнении упражнений в таком режиме, сначала увеличивается максимальное потребление кислорода, затем ускоряется утилизация лактата и, наконец, организм повышает эффективность утилизации кислорода. Высокоинтенсивные тренировки способствуют повышению выносливости сердечно-сосудистой системы без потери силы, скорости и мощности.

Как видим из вышесказанного, можно сделать вывод, что интервальные тренировки с высокой интенсивностью улучшают способность военнослужащих выполнять физические действия с повышенной мощностью в большой промежуток времени. Это особенно необходимо в экстремальных условиях профессиональной деятельности, связанной с напряжением моральных и физических сил в сложной служебно-боевой деятельности. Так же необходимо отметить, что развитие силы на прямую связано с развитием скоростно-силовых качеств военнослужащих, а это уже другие упражнения, способствующие развитию этого качества. Прежде всего, это упражнения связанные со скоростным пробеганием различных дистанций в полной экипировке и переноске грузов на различные расстояния. Достижению результатов в этих упражнениях будет способствовать так же интервальная тренировка с высокой интенсивностью. На фоне усталости, сокращая промежутки для отдыха, мы вновь добиваемся повышения тренировки сердечно-сосудистой системы за счет высокоинтенсивного тренинга.

Таким образом, методы развития качества силы, которые используются на практических занятиях и хорошо описаны в Руководстве по физической подготовке в войсках национальной гвардии Российской Федерации, в основном способствуют улучшению общего уровня силовой подготовки военнослужащих. Однако физическая подготовка в настоящее время должна опираться на новые научные достижения в области практической физической культуры и спорта. Высокоинтенсивная интервальная тренировка, это одно из перспективных направлений в развитии силы на современном этапе развития физического совершенствования.

Использования этого метода на занятиях по физической подготовке способствует лучшему развитию качества силы, активизирует самостоятельность военнослужащих и способствует контролю, за воздействием упражнений на организм. 
Интенсивная интервальная тренировка позволяет обеспечить более качественную подготовку военнослужащих для успешной служебно-боевой деятельности.

$$
* * *
$$

1. Большов А.С. Развитие физических качеств. Силовая подготовка студентов в вузе: учебное пособие. Нижегородский государственный архитектурный университет: - Н.Новгород, ННГАСУ, 2017. - $104 \mathrm{c}$.

2. Муратова И.В., Данилова Н.В. Характеристика и методика развития основных физических качеств: учебно-методическое пособие; Саран, кооперативный институт РУК. - Саранск, 2019. $94 \mathrm{c}$.

3. Наставление по физической подготовке в войсках национальной гвардии Российской Федерации (НФП-2018). - 77c.

4. Руководство по физической подготовке в войсках национальной гвардии Российской Федерации. Москва. 2018. - $310 \mathrm{c}$.

5. Слабоучикова Т.А. Совершенствование физических качеств сотрудников полиции средствами кросс фита: методическое пособие; Екатеринбург: Уральский юридический институт МВД России, 2015. $-40 \mathrm{c.}$

\section{Нуждина М.В. \\ Особенности реализации образовательных услуг туристической направленности}

Нижегородский государственный инженерно-экономический университет (Россия, Княгинино)

doi: $10.18411 / \mathrm{lj}-03-2021-191$

idsp: ljournal-03-2021-191

\section{Аннотация}

В настоящее время в системе образования происходят кардинальные изменения подходов к организации образовательного процесса в учебном заведении. Введение системы многоуровневого образования, создание единого образовательного пространства, переход на ФГОС ВО, осуществление компетентностного подхода, устанавливают необходимость совершенно нового подхода к организации образовательного процесса. Преподаватель учебного заведения должен осуществлять не только функцию транслятора научных знаний, но и уметь использовать инновационные формы преподавания, применять активные и интерактивные образовательные технологии, для осуществления творческой атмосферы обучения.

Преподавателям необходимо целеустремленно и настоятельно овладевать активными и интерактивными формами и технологиями обучения: деловыми играми, тренингами, кейс-технологиями, игровым проектированием, и другими различными приемами, так как именно они развивают основные компетентности обучающихся, формируют базовые для специальности знания, умения и навыки, основывают предпосылки для психологической готовности вводить в практику усвоенные знания, умения и навыки. В то же время, как показывает практика, в настоящее время самое большое использование активные и интерактивные образовательные технологии приобрели не в вузах, а в системе обучающих организаций, в которых для этих целей созданы корпоративные университеты, тренинговые курсы.

Ключевые слова: образовательный процесс, образовательные учреждения, активные методы обучения, интерактивное обучение, активный час, туристскоэкскурсионные мероприятия.

\section{Abstract}

Currently, the education system is undergoing fundamental changes in approaches to organizing the educational process in an educational institution. The introduction of a multilevel education system, the creation of a single educational space, the transition to the Federal State Educational Standard of Higher Education, the implementation of a competence-based approach, establish the need for a completely new approach to the 